\title{
The effect of an educational program based on the theory of brain-based learning on the development of emotional intelligence and some basic skills in volleyball
}

\section{Ayman Mordy said Abdel bary}

Assistant Professor in the Department of theories and applications of collective sports and racket sports- Facult of physical Education, Sadat City University, Egypt.

\section{Abstract}

The research aims to design an educational program using the theory of brain-based learning and to know its effect on the development of emotional intelligence and the level of skill performance of some basic skills in volleyball, The researcher used the experimental method due to its suitability to the nature of this study, and he used one of the experimental designs, which is the experimental design for three groups (two experimental groups and a control group), using pre and post measurement, The basic sample was chosen by the intentional method on the beginners of the Ahli Quesna club, and their number was (40) beginners, the researcher reached the following conclusions: The use of brain-based learning theory has a positive effect on improving the skill level of the skills under discussion, There were no statistically significant differences between the averages of the post measurements between the two experimental research groups in the skill variables under discussion, Based on the results of the research that there is a strong correlation between learning type (auditory - visual) and the follow-up of beginners and the level of skill performance, The more communication and following the appropriate pattern for beginners, the greater the improvement in the level of skill performance.

\section{Introduction and search problem:}

The world is now going through a tremendous revolution in the world of educational technology and its spread in the world of teaching and perhaps the conflict between countries now in order for each of them to keep pace with the tremendous progress in scientific capabilities and modern thought, which in turn keeps pace with that existing technological revolution and all this is in order to improve the teaching process and develop education and learning which in turn depends On innovative thinking and creativity and training those in charge of the education process to keep pace with this tremendous technological revolution.

Preparing the learner who is able to play a positive role requires the need to search for teaching strategies that help the learner build meaning for what he learns and develop in it his ability to solve problems, so he relies on himself in learning and is not expected to provide him with ready-made solutions to the scientific problems facing him. (3:53)

Jensen 2000 AD believes that the theory of brain-based learning emphasizes learning with the presence of the mind, with the presence of high arousal, realism, pleasure, excitement, fun and cooperation, the absence of threat, the multiplicity and overlap of systems in the educational process, and other characteristics of harmonious learning with the brain. (10:32) 
The functions of the two hemispheres of the brain differ in its approach to the type of information contained in the educational methods to which the individual is exposed, so the left hemisphere works in verbal, analytical, symbolic, abstract, motivational, numerical, logical and written activities, while the right hemisphere deals with synthetic, spatial, holistic, imaginary, sensory and nonverbal activities, which means that the left hemisphere It controls analytical thinking, especially language for reading and writing, and works on preparing information in a sequential and sequential fashion, The right hemisphere controls innovation, verbal skills and intuition. (8: 89)

Through the researcher's work as a trainer, he found that the beginners have a problem in understanding volleyball skills because of the different individual differences between beginners in comprehending skills, which must take into account the learning styles through an electronic scale that takes place on the beginners to know their learning styles (auditory pattern - visual pattern movement pattern) and then The application of the educational program using the theory of learning to the brain, and the researcher believes that the teaching method for the skills followed depends entirely on the teacher in providing skills by performing a model and sometimes verbal explanation and exercises for basic skills in volleyball, and does not allow the beginners to participate positively in learning to keep pace with contemporary trends in the field of education To improve the level of beginners' performance, it also does not take into account the individual differences between beginners and does not allow them to choose the level of difficulty according to their level, nor provides them with individual feedback for each beginner alone, Enjoy learning and motivate them to take responsibility for their own learning and increase interaction and communication between the novice Yen and their teacher, which helps the teacher to identify weaknesses and strengths in their understanding and level of awareness of skills as they include strategies and educational activities that address the right (emotional) and left (logical) hemispheres of the brain, which led to the creation of harmony and integration between the two halves, where the emotional response occurs first From the emotional brain, followed by the mental response from the logical brain to bring about balance and integration between them.

Accordingly, the idea of the current research, which is focused on identifying the extent of the effect of using the theory of brain-based learning on the level of skill performance in an attempt to employ technology in the service of beginners, and therefore this study is one of the studies that is based on the use of a social network to teach some skills Basic in volleyball through a mobile phone or a laptop, and the program is based on the use of visual effects by watching the visual or visual effects for visual style beginners, and by listening and a detailed 
description of those skills (sound effects) for beginners of the auditory style and employing that in Tradition and actual practice through the practical application of the skills under discussion.

\section{Research objectives:}

The research aims to design an educational program using the theory of brain-based learning and to know its effect on the development of emotional intelligence and the level of skill performance of some basic skills in volleyball.

\section{Research hypotheses:}

1. There are statistically significant differences between the pre-measurement and the post-measurement for the two experimental research groups and the control group in some of the skill variables under discussion in favor of the post measurement.

2. There are statistical significant differences between the post-measurements between the two experimental research groups and the control group in some of the skill variables under discussion.

3. There is a difference in the rates of opinions and impressions of the beginners in the two experimental research groups using brain-based learning to learn some basic skills in volleyball.

\section{Search procedures:-}

\section{First, the research methodology:}

The researcher used the experimental method due to its suitability to the nature of this study, and he used one of the experimental designs, which is the experimental design for three groups (two experimental groups and a control group), using pre and post measurement.

\section{Second: the research sample:}

The basic sample was chosen by the intentional method on the beginners of the Ahli Quesna club, and their number was (40) beginners at a rate of $33.33 \%$ of the total research community, They were distributed in an intentional way to three groups after conducting the electronic scale to determine the learning style that corresponds to their learning type (the first group (visual type) The second group (audio type), the control group, and the size of the survey sample reached (20), beginning from the Al-Hai El-Bahri club in Shebin Al-Kom, and it was $16.67 \%$ of the total research population and outside the basic research sample in order to calculate the scientific transactions.

- Homogeneity and Equalization of the groups research sample. attachment (1)

Third: Data collection tools and means:

To collect data and information related to this research, the following tools and methods were used:

1- Reference survey. attachment (2) 
2- Personal interviews. attachment (3)

3- Tools and devices used in the research. attachment (4)

4- Research Forms: attachment (5)

5- Tests used: attachment (6)

Fourth: ExplorationStudies:

1- Validation physical and skill tests. attachment (7)

2- Stability of physical and skill tests. attachment (8)

Fifth: The proposed educational program:

The researcher has prepared the educational program so that it includes (12) weeks of 2 units per week, meaning that the program includes (24) educational units, the unit time is 90 minute, while the content is applied by research during the preparatory part of the unit and its time is 35 minute, and the program includes (3) educational skills To master them and improve performance, the table shows the time distribution of the two proposed programs.

Sixth: Steps to apply the search:

1- per measurements:

The researcher conducted the pre-measurement of the two experimental research of the physical and skill variables on Tuesday 11/8/2020 AD.

\section{2- Implementation of the basic experiment:}

The researcher applied the two educational programs from Saturday $15 / 8 / 2020$ AD to Wednesday 4/11/2020 AD, and the duration of the two programs was (12) weeks.

\section{3- post measurement:}

After the end of the specified period for implementing the basic experiment, the researcher made the post measurements of the research sample of the skill variables and the variation in the rates of opinions and impressions of the beginners on Saturday 7/11/2020 AD.

\section{Seventh: Statistical Treatments:}

- Descriptive statistics: measures of central tendency - standard deviation coefficients of torsion and flattening, $\mathrm{T}$ test.

- Correlation coefficient to calculate the stability of physical and skill tests.

- One-way analysis of variance.

- Calculation of the lowest significant difference LSD, Percentage improvement by percentages. 


\section{Presentation and discussion of results:}

Firstly: Presentation and discussion of the results of the first hypothesis:

Table (9)

The significance of the differences between the mean of the two measures

(pre - post) For the first experimental group (visual type) in skill tests

\begin{tabular}{|c|c|c|c|c|c|c|c|c|}
\hline \multirow{3}{*}{ Test title } & \multirow{3}{*}{$\begin{array}{c}\text { measu } \\
- \text { unit }\end{array}$} & & & & & & \multicolumn{2}{|c|}{$\mathrm{N}=18$} \\
\hline & & \multicolumn{2}{|c|}{$\begin{array}{c}\text { Pre } \\
\text { measurement }\end{array}$} & \multicolumn{2}{|c|}{$\begin{array}{c}\text { Post } \\
\text { measurement }\end{array}$} & \multirow{2}{*}{$\begin{array}{c}\text { mean } \\
\text { differences }\end{array}$} & & $\begin{array}{l}\text { Improvemen } \\
\text { t percentage }\end{array}$ \\
\hline & & mean & St.d & mean & St.d & & & \\
\hline Over hand Serve & point & 1.30 & 0.82 & 9.90 & 1.20 & 8.60 & $21.50^{*}$ & 661.54 \\
\hline Over head pass & Rep & 9.20 & 0.63 & 18.20 & 2.15 & 9.00 & $14.23^{*}$ & 97.83 \\
\hline under hand pass & Rep & 5.00 & 0.82 & 14.20 & 1.32 & 9.20 & $16.61 *$ & 184.00 \\
\hline
\end{tabular}

Tabular " $t$ " value at the level of significance $(0.05)=(1.74)$

It is clear from table 9 that there are statistically significant differences at the level (0.05) between the mean measurement (Pre - Post) of the experimental group in the level of skill variables under consideration and in favor of the post measurement.

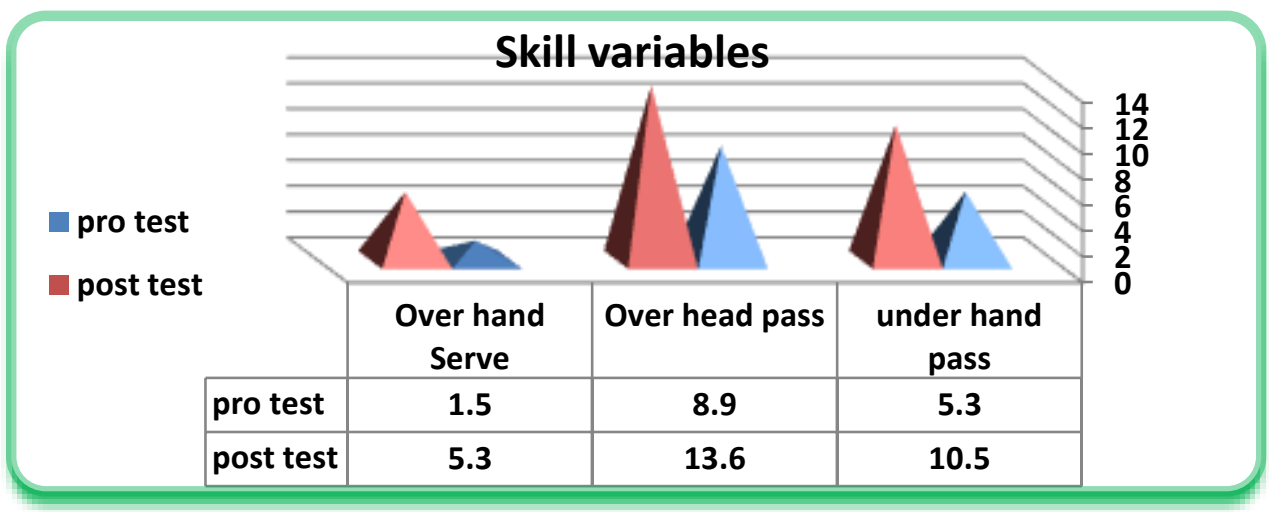

Figure (1)

The skill variables of the visual type group

Table (10)

The significance of the differences between the mean of the two measures (pre

- post) For the second experimental group (auditory type) in skill tests

\begin{tabular}{|c|c|c|c|c|c|c|c|c|}
\hline \multirow{3}{*}{ Test title } & \multirow{3}{*}{$\begin{array}{c}\text { measu- } \\
\text { unit }\end{array}$} & \multirow{2}{*}{\multicolumn{2}{|c|}{$\begin{array}{c}\text { Pre } \\
\text { measurement }\end{array}$}} & \multirow{2}{*}{\multicolumn{2}{|c|}{$\begin{array}{c}\text { Post } \\
\text { measurement }\end{array}$}} & \multirow{3}{*}{$\begin{array}{c}\text { mean } \\
\text { differences }\end{array}$} & \multicolumn{2}{|c|}{$\mathrm{N}=12$} \\
\hline & & & & & & & $\begin{array}{c}\mathbf{T} \\
\mathbf{S}\end{array}$ & $\begin{array}{c}\text { Improvemen } \\
\text { t percentage }\end{array}$ \\
\hline & & mean & St.d & mean & St.d & & & $\%$ \\
\hline Over hand Serve & point & 1.90 & 0.74 & 8.40 & 1.58 & 6.50 & 9.94* & 342.11 \\
\hline Over head pass & Rep & 9.80 & 0.92 & 17.50 & 2.27 & 7.70 & $7.87^{*}$ & 78.57 \\
\hline under hand pass & Rep & 5.60 & 0.97 & 12.60 & 1.90 & 7.00 & $11.39 *$ & 125.00 \\
\hline
\end{tabular}

Tabular " $t$ " value at the level of significance $(0.05)=(1.80)$

It is clear from table 10 that there are statistically significant differences at 
the level (0.05) between the mean measurement (Pre - Post) of the experimental group in the level of skill variables under consideration and in favor of the post measurement.

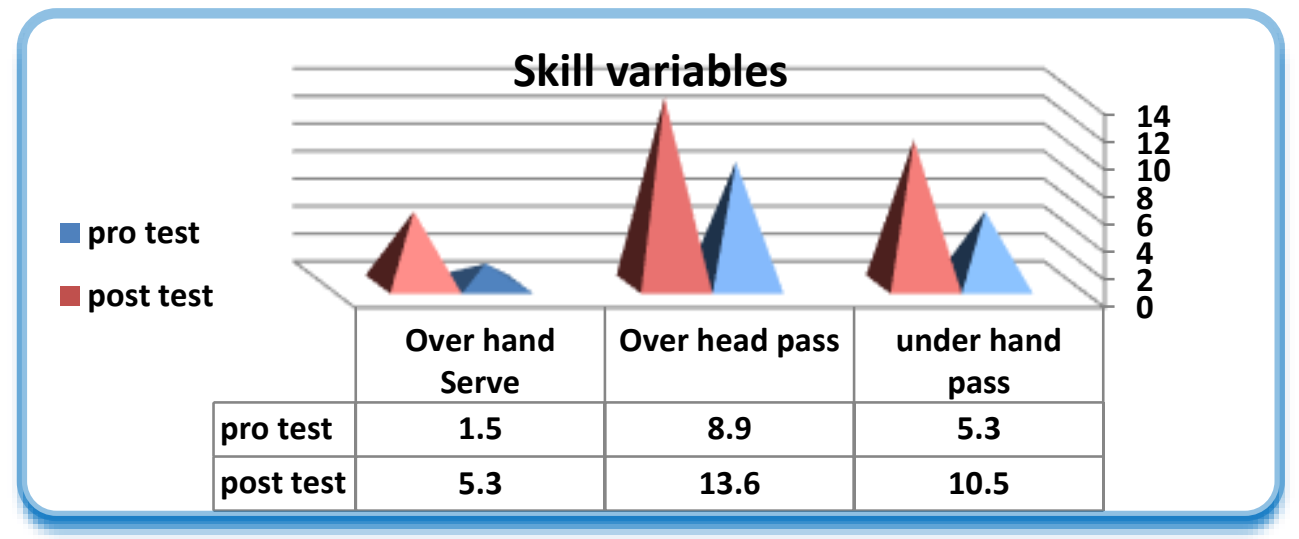

Figure (2)

The skill variables of the auditory type group

Table (11)

The significance of the differences between the mean of the two measures (pre - post) For the Controllers group in skill tests

\begin{tabular}{ccccccccc}
\multirow{2}{*}{ Test title } & \multirow{2}{*}{$\begin{array}{c}\text { measu- } \\
\text { unit }\end{array}$} & \multicolumn{2}{c}{$\begin{array}{c}\text { Pre } \\
\text { measurement }\end{array}$} & \multicolumn{2}{c}{$\begin{array}{c}\text { Post } \\
\text { measurement }\end{array}$} & $\begin{array}{c}\text { mean } \\
\text { differences }\end{array}$ & $\begin{array}{c}\text { T } \\
\text { Value }\end{array}$ & $\begin{array}{c}\text { Improvemen } \\
\text { t percentage } \\
\boldsymbol{\%}\end{array}$ \\
\cline { 3 - 9 } & & mean & St.d & mean & St.d & & & \\
\hline Over hand Serve & point & 1.50 & 0.53 & 5.30 & 0.95 & 3.80 & $9.78^{*}$ & 253.33 \\
\hline Over head pass & Rep & 8.90 & 0.32 & 13.60 & 1.20 & 4.70 & $13.69^{*}$ & 52.81 \\
\hline under hand pass & Rep & 5.30 & 0.48 & 10.50 & 1.43 & 5.20 & $14.02^{*}$ & 98.11 \\
\hline
\end{tabular}

Tabular " $t$ " value at the level of significance $(0.05)=(1.83)$

It is clear from table 11 that there are statistically significant differences at the level (0.05) between the mean measurement (Pre - Post) of the Controllers group in the level of skill variables under consideration and in favor of the post measurement.

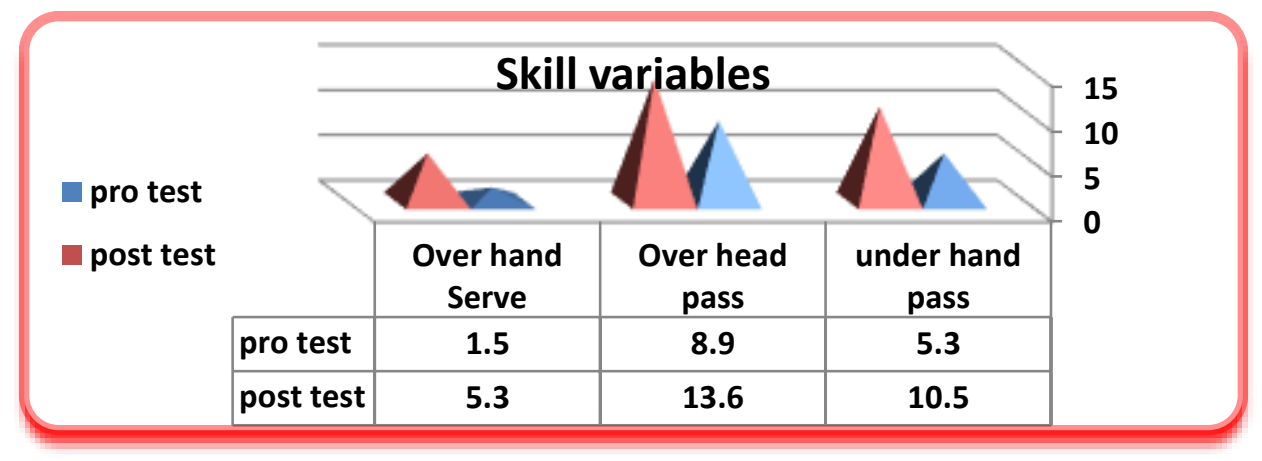

Figure (3)

The skill variables of the Controllers group 
It is clear from table (9) (10) (11) that there are statistically significant differences between the means of the pre and post measurements of the three research groups in the level of performance of the skills of the skills under consideration, which includes (Over hand Serve - Over head pass - under hand pass) in favor of the post measurement, where It is evident that the calculated " $t$ " value is greater than the tabular " $t$ " value at a significant level $(0.05)$ for the skills under consideration, which confirms the existence of statistically significant differences in favor of the post-measurement.

The researcher attributes these differences between the pre and post measurements of the beginners of the two experimental research groups in the level of skill performance of the skills under consideration to their use of brainbased learning that provided them with a successful learning environment that contributed to their understanding of the technical stages of the skills under study in a good way, and then reaching the ideal skill performance for each A technical stage for each skill due to what is included in brain-based learning of electronic learning through which it is done and the effect of those exercises that they carried out, represented by collecting images related to the skills in question from various sources and watching video films and CDs related to skills that had an impact on developing the awareness of beginners themselves Their pride in themselves and their sense of satisfaction with what they have accomplished encourages them to accomplish other skills if requested from them, as it had a great impact in enabling them to control the level of performance and in comparison with others in the educational units and educational resources vary in the learning environment through what the teacher requests from the beginners From seeing the suggested video on the skills in question through an individual view and then asking them to identify the most important parts of the vision A study in skill, and the dialogue and discussion takes place on the questions that address the two hemispheres of the brain that follow the written and audible text of the two research groups under the supervision of the researcher and all this contributed to improving the skill level of the beginners of the two experimental research groups.

This result is consistent with the results of the study of Hamdan Mohamed 2008 (8) and Ahmad Anwar 2015 (3), where the results of those studies indicated that the use of brain-based learning had a positive effect on the skill side, which led to improving the level of skill performance in favor of the post-measurement of the two experiments groups.

In this regard, Afaf Abd al-Karim 1990 AD (1) indicates that the basis of the traditional method is the direct relationship between the teacher's alarms and the learner's response. Movement modes, location, start, timing, and end time for the learning and rest period. 
This is in agreement with the results of the studies of Ahmad Abdel kadir and Ashraf Youssef 2007 AD (2), Hamdan Mohamed 2010 AD (8) Sabah Abdallah 2010 AD (17) where the results of those studies indicated that the classroom method cannot be overlooked as it leads to good learning and has an effect to advance the level of skill performance.

With this result, what came in the first hypothesis of the research is achieved, which states that "There are statistically significant differences between the pre-measurement and the post-measurement for the two experimental research groups and the control group in some of the skill variables under discussion in favor of the post measurement".

Second: Presentation and discussion of the second hypothesis:

Table (12)

Analysis of variance between the three groups in skill tests

\begin{tabular}{|c|c|c|c|c|c|}
\hline variables & $\begin{array}{l}\text { The source of } \\
\text { the contrast }\end{array}$ & $\begin{array}{l}\text { Sum of } \\
\text { squares }\end{array}$ & df & Mean squares & $\mathbf{F}$ \\
\hline \multirow{3}{*}{$\begin{array}{l}\text { Over hand } \\
\text { Serve }\end{array}$} & Between groups & 110.07 & 2 & 55.03 & \multirow{3}{*}{$34.24 *$} \\
\hline & Within groups & 43.40 & 37 & 1.61 & \\
\hline & total & 153.47 & 39 & & \\
\hline \multirow{3}{*}{$\begin{array}{c}\text { Over head } \\
\text { pass }\end{array}$} & Between groups & 122.87 & 2 & 61.43 & \multirow{3}{*}{$15.87 *$} \\
\hline & Within groups & 104.50 & 37 & 3.87 & \\
\hline & total & 227.37 & 39 & & \\
\hline \multirow{3}{*}{$\begin{array}{c}\text { under } \\
\text { hand pass }\end{array}$} & Between groups & 68.87 & 2 & 34.43 & \multirow{3}{*}{$13.98 *$} \\
\hline & Within groups & 66.50 & 37 & 2.46 & \\
\hline & total & 135.37 & 39 & & \\
\hline
\end{tabular}

The value " $F$ " is at the level of significance (0.05) and the $D F(2.27)=3.58$

It is clear from Table (12) that there are statistically significant differences at a significant level (0.05) between the measurements of the pre and post research sample for the three groups in the variables (Over hand Serve - Over head pass under hand pass), where the calculated value of $(\mathrm{F})$ was higher than $(\mathrm{F})$ tabular values at a significant level (0.05), and to clarify the significance of the differences between these measures, the researcher will calculate the lowest significant difference using the LSD test as shown in Table (13).

Table (13)

The significance of the differences between the mean measurements in the skill tests

\begin{tabular}{cccccc}
\hline \multirow{2}{*}{ variables } & \multirow{2}{*}{ Groups } & \multirow{2}{*}{ Mean } & \multicolumn{3}{c}{$\mathrm{N}=40$} \\
\cline { 4 - 6 } & & & \multicolumn{2}{c}{ Differences between groups } \\
\hline $\begin{array}{c}\text { Over hand } \\
\text { Serve }\end{array}$ & Visual group & 9.90 & & 1.50 & $4.60^{*}$ \\
\cline { 2 - 6 } & Audio group & 8.40 & & & $3.10^{*}$ \\
\hline
\end{tabular}




\begin{tabular}{ccccc}
\hline & Control group & 5.30 & & \\
\hline \multirow{2}{*}{$\begin{array}{c}\text { Over head } \\
\text { pass }\end{array}$} & Visual group & 18.20 & & $4.60^{*}$ \\
\cline { 2 - 5 } & Audio group & 17.50 & & $-3.90^{*}$ \\
\cline { 2 - 5 } $\begin{array}{c}\text { Control group } \\
\text { under }\end{array}$ & 13.60 & & 3.70 \\
\cline { 2 - 5 } hand pass & Audio group & 14.20 & 1.60 & 2.10 \\
\cline { 2 - 5 } & Control group & 10.50 & & \\
\hline
\end{tabular}

Where the differences came in favor of experimental research groups (brainbased learning), And the researcher returns a reason for The two experimental research groups outperformed the control group in the level of skill performance to using the educational program using brain-based learning through the (whatSapp) program, Which is done by the method of displaying the visual skills of the visual and auditory group of the auditory group before its performance and the beginner returning to the program whenever needed during the educational unit and that she sees the model of the motor skill that has the stability of performance no matter how often the model is presented in the appropriate manner with its abilities and needs and thus has a positive role in forming the perception The correct movement of the motor skill in the mind of the beginner and proves it, as well as the freedom to roam within the program and the link between the technical and educational aspects, how to correct errors and the auxiliary tools, which removes the confusion that may occur in the performance of the beginners during the educational unit in addition to the presentation of the skill in an interesting and attractive way that led to the removal of the difficulties that they encountered during the process Educational as it is characterized by a degree of difficulty during its performance, And thus reduce the frequent presence of common mistakes that may appear among beginners during the application and take advantage of this time that is wasted to correct those errors and repeat the application again, and therefore this time is invested in increasing the time of practice and practical application of the skill, this is in addition to the teacher explanation during the educational unit and the diversity Methods for the teacher to display the learned skill in more than one way, as well as taking into account the individual differences between the beginners so that each beginner can walk in learning according to her need and abilities, and therefore the brain-based learning combines both the advantages of elearning through the (whatSapp) program and classroom education all this gave beginners an opportunity Great to understand the successive stages of the skill performance properly, which positively affected their performance of the learned skill in an ideal way depending on the feedback of the beginner, while the traditional method relies on the use of theoretical explanation and model by the teacher or fixed images with references, which reduces their motivation to learn, but the modern view in Learning looks at the learner as a living, interacting 
organism and its goal is its growth and maturity. The goal is not to preserve information, but rather to construct The learner uses knowledge according to the way he deals with it, as she considers him a builder of his knowledge.

This is in agreement with the studies of Duman 2006 AD (9) Nadia Samih 2004 AD (15) Mona Hussein 2005 AD (14) where the results of those studies indicated that blended learning (electronic learning - classroom education through feedback) was more effective for the experimental group in improving The level of skill performance compared to the control group.

From the above, what came in the second hypothesis of the research is achieved, which states that "There are statistical significant differences between the post-measurements between the two experimental research groups and the control group in some of the skill variables under discussion".

\section{Third: Presentation and discussion of the third hypothesis: -}

Table (14)

The opinions and impressions of the beginners of the

two experimental research groups

\begin{tabular}{ccccccccccc}
\hline $\mathbf{N}$ & $\begin{array}{c}\text { Estimate } \\
\text { d Total }\end{array}$ & $\begin{array}{c}\text { Relative } \\
\text { Weight }\end{array}$ & $\boldsymbol{P}$ & $\begin{array}{c}\text { Estimate } \\
\text { d Total }\end{array}$ & $\begin{array}{c}\text { Relative } \\
\text { Weight }\end{array}$ & $\boldsymbol{P}$ & $\begin{array}{c}\text { Estimate } \\
\text { d Total }\end{array}$ & $\begin{array}{c}\text { Relative } \\
\text { Weight }\end{array}$ & $\begin{array}{c}\text { Estimated } \\
\text { Total }\end{array}$ & $\begin{array}{c}\text { Relative } \\
\text { Total } \\
\text { weight }\end{array}$ \\
\hline 1 & 30 & $100 \%$ & 11 & 30 & $100 \%$ & 21 & 30 & $100 \%$ & - & - \\
\hline 2 & 27 & $90 \%$ & 12 & 30 & $100 \%$ & 22 & 26 & $86.67 \%$ & - & - \\
\hline 3 & 28 & $93.33 \%$ & 13 & 0 & $0.0 \%$ & 23 & 25 & $83.33 \%$ & - & - \\
\hline 4 & 0 & $0.0 \%$ & 14 & 0 & $0.0 \%$ & 24 & 30 & $100 \%$ & - & - \\
\hline 5 & 27 & $90 \%$ & 15 & 30 & $100 \%$ & 25 & 30 & $100 \%$ & - & - \\
\hline 6 & 28 & $93.33 \%$ & 16 & 30 & $100 \%$ & 26 & 30 & $100 \%$ & - & - \\
\hline 7 & 0 & $0.0 \%$ & 17 & 30 & $100 \%$ & 27 & - & - & - & - \\
\hline 8 & 24 & $80 \%$ & 18 & 30 & $100 \%$ & 28 & - & - & - & - \\
\hline 9 & 0 & $0.0 \%$ & 19 & 30 & $100 \%$ & 29 & - & - & - & - \\
\hline 10 & 29 & $96.67 \%$ & 20 & 30 & $100 \%$ & 30 & - & - & - & - \\
\hline & $\mathbf{1 9 3}$ & & & $\mathbf{2 4 0}$ & & & $\mathbf{1 7 1}$ & & $\mathbf{6 0 4}$ & $\mathbf{7 7 . 4 4 \%}$ \\
\hline
\end{tabular}

It is evident from Table (14) that the relative weight of the responses of the beginners in the two experimental research groups was $77.44 \%$. This indicates that there is a positive effect on the opinions and attitudes of the beginners of the two experimental research groups towards the use of social media (WhatsApp) Within the brain-based learning program, in learning some of the skills under consideration.

The researcher returns this to the nature of social media networks (Whatsapp), where they have a completely new and distinctive style that is presented to the beginners and this is with the testimony of the beginners themselves, also because they work to attract attention through a clear and interesting vision of the skills and focus the visual senses through imagining and 
visualizing the concept or Information or facts through the use of visual stimuli, that is, such as drawings, videos, and models of the visual type group and the focus of the auditory senses by receiving information from various sources (teacher, computer programs, lectures, audio films) For the auditory type group during the interesting presentation, as well as the freedom to navigate the program and display the motor performance of skills Through the visual multimedia of the visual style group, the visual multimedia of the auditory style group, all this aroused the interest of the beginners and their willingness to absorb, learn correctly and focus on what is presented, And it increased the passion and motivation of the beginners towards making more effort to learn the skills as the senses of the beginners were stimulated and thus their focus increased as all the models agreed on the necessity of gradual application of the stages of brain-based learning, starting with preparation and passing through providing educational experience and expanding it through the use of activities and ending with the evaluation and application Knowledge in new situations, and this is consistent with what the results of some studies indicated that using more than one sense during teaching has an effective effect on the learning process, Which confirms the opinion of Jensen 2000 AD (10) that the theory of brain-based education emphasizes learning with the presence of the mind, with the presence of high and realistic arousal, pleasure, excitement, fun and cooperation, the absence of threat, the multiplicity and overlap of systems in the educational process and other characteristics of harmonious learning with the brain.

This is consistent with what Mahmoud Anan and Mostafa Bahi 2001 AD (12) have indicated that the internal motivation emanating from within the individual himself helps the individual to overcome the difficulties and obstacles that require more effort, courage and will, or because of the aesthetic pleasure resulting from the grace and coordination of performance, Or the result of an internal motivation stemming from outside the individual himself, which stimulates and directs behavior towards practice or athletic performance.

Thus, the validity of what came in the third hypothesis of the research hypotheses has been verified, which states that "There is a difference in the rates of opinions and impressions of the beginners in the two experimental research groups using brain-based learning to learn some basic skills in volleyball".

\section{Conclusion:}

In light of the nature of this study, the sample, the methodology used, the results of the statistical analysis, the researcher reached the following conclusions:

1. The use of brain-based learning theory has a positive effect on improving the skill level of the skills under discussion. 
2. There were no statistically significant differences between the averages of the post measurements between the two experimental research groups in the skill variables under discussion.

3. Based on the results of the research that there is a strong correlation between learning type (auditory - visual) and the follow-up of beginners and the level of skill performance, The more communication and following the appropriate pattern for beginners, the greater the improvement in the level of skill performance.

\section{Recommendations:}

In light of the conclusions that were based on the nature of the study, the sample, the method used and the results of the statistical analysis, the researcher was able to identify recommendations that benefit work in the field of volleyball education as follows:

1. Directing the results of this study and the educational program used and the steps for its implementation to those working in the volleyball field to benefit from these results.

2. One must rely on the strengths of the right side of the brain in planning curricula and choosing activities.

3. Study the effect of using different strategies and strategies for remembering and correct thinking on the development of mental processes on both sides of the brain.

\section{References:}

1- Afaf Abdel Karim

4- Ahmed Najdi Mona Abdel Hadi

5- Ali Mostafa Taha

7- Clark, Barbara

8- Hamdan Mohamed Ali

9- Hardiman dowman, Mariale.
: Teaching Methods in Physical Education and Sports, munsha'at almaearif, Alexandria, 1990 AD.

: Modern educational methods, methods and strategies, first edition, dar alfikr alaraby, Cairo, $2003 \mathrm{AD}$.

: Volleyball: History - Education - Training - Analysis Law, dar alfikr alaraby, 1st Edition, Cairo, 1999 AD.

: Activating Learning - The Educational Model in the Classroom, First Edition, Dar Al-Furqan for Publishing and Distribution (translated by Yaqoub Nashwan and Muhammad Khattab), Amman, 2004.

: Effectiveness of a proposed model on structural learning and brain theory for teaching science to middle school students, unpublished $\mathrm{PhD}$ thesis, Faculty of Education, Helwan University, 2008 AD.

:The Brain Targeted Teaching Model: A comprehensive model for Classroom instruction and School reform In The Praeger Handbook of Learning and the Brain,Westport, CN: Greenwood Publishing Group, 2006. 
10- Jensen ,Eric

11- Mahmoud Abdel Halim Mansi

12- Mahmoud Abdel Fattah Anan Mostafa Hussain Bahi

13- Michael Miller

15- Nadia Samih Al Salti

16- Ozden, Muhammet and Gultekin, Mehmet

18- Weimer, $\mathbf{C}$.,

19- Zaki Mohamed Hassan
:Brain-based Learning, Sandiago, CA:The Brain Store, 2000.

: Learning (concept, models, applications), The AngloEgyptian Library, Cairo, 2003 AD.

$:$ An Introduction to Sports Psychology, Al Kitab Center for Publishing, Cairo, 2001 AD.

:Hemispheric Enconding Asymmetry is Apparent than Real. Journal of Cognitive Neuroscience, 14(5),702-708, 2002. Brain based learning, First edition, dar Maisarah for Publishing and Distribution, Amman, 2004. :The Effects of Brain-Based Learning on Academic Achievement and Retention of Knowledge in Science Course, Electronic Journal of Science Education, 12(1),117,2008 .

Engaged learning through the use of brain based teaching : Acase study of eight middle school classroom, Ph.D., Dissertation, northern Illinois university, 2007.

: Volleyball (Modern Technologies in Teaching and Teaching), multaqi alfikr, The Egyptian Library, Alexandria, $2000 \mathrm{AD}$. 